\title{
Total and Methyl Mercury Contents and Distribution Characteristics in Cicada, Cryptotympana atrata (Fabricius)
}

\author{
Dongmei Zheng $\cdot$ Zhongsheng Zhang • \\ Qichao Wang
}

Received: 18 September 2009/ Accepted: 27 April 2010/Published online: 14 May 2010

(C) The Author(s) 2010. This article is published with open access at Springerlink.com

\begin{abstract}
Total and methyl mercury concentrations of cicada bodies, wings, and exuviae were investigated to study the mercury distribution characteristics. Results indicated that total and methyl mercury concentrations of cicada bodies were $2.64 \mathrm{mg} / \mathrm{kg}$ and $123.93 \mathrm{ng} / \mathrm{g}$ on average, respectively. In cicada tissues, total mercury concentrations were found to increase in the order of exuviae $(0.50 \mathrm{mg} / \mathrm{kg}$ on average $)<$ wings $(0.98 \mathrm{mg} / \mathrm{kg}$ on average) $<$ cicada bodies ( $2.64 \mathrm{mg} / \mathrm{kg}$ on average) and methyl mercury concentrations of cicada bodies were $123.93 \mathrm{ng} / \mathrm{g}$ on average and were the highest. Methyl mercury concentrations accounted for about $4.69 \%$ of total mercury in cicada bodies and most mercury was in inorganic forms in cicada. Sex differences of total mercury concentrations were significantly great $(F=8.433, p<0.01)$ and total mercury concentrations of the males, which were $3.38 \mathrm{mg} /$ $\mathrm{kg}$ on average, were much higher. Correlation analysis showed that neither total nor methyl mercury concentrations of cicada bodies was significantly related to the corresponding contents of soil $(r=0.0598, p>0.05)$.
\end{abstract}

\section{Zheng $(\bowtie)$}

Key Laboratory of Regional Environment and Eco-Remediation, Ministry of Education, Shenyang University, 110044 Shenyang, People's Republic of China

e-mail: zhengdongmei126@163.com

\section{Z. Zhang . Q. Wang}

Key Laboratory of Wetland Ecology and Environment, Institute of Northeast Geography and Agroecology, Chinese Academy of Science, 130012 Changchun,

People's Republic of China

\section{Z. Zhang}

Graduate University of Chinese Academy of Sciences, 100049 Beijing, People's Republic of China
Keywords Mercury $\cdot$ Methyl mercury $\cdot$ Distribution · Cicada

Mercury is recognized as a very toxic metal in the environment and can result in poisoning of wild animals and humans due to the fact that it can be biomagnified along the food chains (Mason et al. 1995; Boening 2000). Previous mercury researches have focused primarily on aquatic organisms, including fishes (Baeyens et al. 2003; Campbell et al. 2008) and invertebrates (Martin and Wang 2004). It is reported that most mercury in fish muscles was in methylated form (Baeyens et al. 2003). In recent years, total and methyl mercury pollution in terrestrial animals are recognized as significant problem, such as mammals (Horai et al. 2006), birds (Longcore et al. 2007), invertebrates (Heikens et al. 2001), insects (Devkota and Schmidt 2000), and reptiles (Jones and Holladay 2006). But still there is little research on the long-lived insects, such as cicada.

Field studies indicated that mercury can be taken up by insects and transferred to organisms occupying higher trophic level (Zhang et al. 2009). Some insects could accumulate large amounts of mercury and are regarded as the bio-indicator of mercury pollution in soil (Hsu et al. 2006). Cicada come out from the soil in late spring and are foods of many birds and entomophagous insects. Mercury can be absorbed efficiently by cicada (Magicicada cassini) and the mercury concentrations in males are significantly higher than that in females of the same species (Heckel and Keener 2007). Cicada with high mercury contents might threat people' s health because cicada and their exuivae are important materials of Chinese traditional medicine.

Cicada is the representative long-lived insect species with special living habits, but little has been known about the mercury distribution characteristics in cicada, and the 
routes of cicada exposed to mercury are complex and still not determined. The primary objective of this study is to investigate total and methyl mercury accumulation in their bodies, hymenopterous wings and exuviae, and then mercury distribution characteristics in cicada are discussed in mercury-contaminated area. It is hoped to reveal the mercury pollution in the long-lived insects and help assess the health of terrestrial ecosystem throughly.

\section{Materials and Methods}

Huludao City is an important non-ferrous smelting and chemical industry area in northeast China. Mercury pollution is serious due to one chlor-alkali plant and two zinc smelteries there. Wuli River and Cishan River are two main rivers in the city. In the present study, cicada are collected from 10 sites by hand, of which most are close to the two Rivers: Huafei Bridge (S1), Huagong Bridge (S2), Huaji Bridge (S3), Wuli bridge (S4), the North bridge of Cishan(S5), Daochi village (S6), the South bridge of Cishan (S7), Cishan village (S8), Longwan Park(S9), and the new residential area (S10) (Fig. 1).

Cicada $(n=67)$ and their exuviae $(n=235)$ were collected, sealed in polythene bags and preserved in portable refrigerator at $4^{\circ} \mathrm{C}$ in field. In laboratory, samples were washed with deionised water to remove mercury attached on the surface, distinguished the female and male, cut off their wings, dried them at $60^{\circ} \mathrm{C}$ to constant weights (Hsu et al. 2006), ground the samples to homogenous powders in a quartz bowl, and preserved in polythene bags in refrigerator at $-4^{\circ} \mathrm{C}$ before used.

Soil $(n=62)$ was collected at the same places where cicada were trapped, sealed in polythene bags, then brought back to laboratory, dried at room temperature, ground to pass an 80-mesh nylon sieve, and preserved in polythene bags before use.

Total mercury of soil, cicada bodies, wings and exuviae were extracted following the method of $\mathrm{H}_{2} \mathrm{SO}_{4}-\mathrm{HNO}_{3}-$
$\mathrm{V}_{2} \mathrm{O}_{5}$. All forms of $\mathrm{Hg}$ in samples were converted to $\mathrm{Hg}^{2+}$, and then $\mathrm{Hg}^{2+}$ was reduced to elemental $\mathrm{Hg}$ by addition of $20 \% \mathrm{SnCl}_{2}$ solution. Cold atomic absorption technique was used to determine the total $\mathrm{Hg}$ with $\mathrm{F} 732 \mathrm{-V} \mathrm{Hg}$ detector whose detection limit is $5 \times 10^{-2} \mathrm{ng} / \mathrm{g}$.

$\mathrm{MeHg}$ in soil, cicada bodies and cicada exuviae were extracted firstly and then separated using the method described by Sun et al. (2007). $0.500 \mathrm{~g}$ of soil and biologic samples were weighed into a $50 \mathrm{~mL}$ polyethylene centrifuge tube. About $5 \mathrm{~mL} 6 \mathrm{~mol} / \mathrm{L} \mathrm{HCl}$ was added to extract all forms of mercury. The tube was placed overnight and then was ultrasonicly cleaned for $2 \mathrm{~h}$. After that, tube was centrifugated at $3,000 \mathrm{rpm}$ for $15 \mathrm{~min}$. The supernatant fluid was transferred into a $10 \mathrm{~mL}$ polyethylene centrifuge tube; $2 \mathrm{~mL}$ of $\mathrm{CH}_{2} \mathrm{Cl}_{2}$ was added and shaken for $1 \mathrm{~h}$ to extract organomercury compounds into the $\mathrm{CH}_{2} \mathrm{Cl}_{2}$ phase. After centrifuging at 3,000 rpm for $15 \mathrm{~min}$, the $\mathrm{CH}_{2} \mathrm{Cl}_{2}$ phase was transferred into a $50 \mathrm{~mL}$ glass tube; an additional $2 \mathrm{~mL}$ of $\mathrm{CH}_{2} \mathrm{Cl}_{2}$ was added into the $10 \mathrm{~mL}$ polyethylene centrifuge tube again to remove any remaining MeHg. The same steps repeated on the same sediment sample. Finally, $5 \mathrm{~mL}$ deionized water was added into the $50 \mathrm{~mL}$ glass tube, which had contained the $4 \mathrm{~mL} \mathrm{CH}_{2} \mathrm{Cl}_{2}$ phase. The $50 \mathrm{~mL}$ glass tube was placed in a $60^{\circ} \mathrm{C}$ water bath and was aerated by $\mathrm{N}_{2}$. The $\mathrm{CH}_{2} \mathrm{Cl}_{2}$ was blown off and the organomercury compounds were left in the water phase. Finally, $1 \mathrm{~mL} \mathrm{1:1} 18 \mathrm{~mol} / \mathrm{L} \mathrm{H}_{2} \mathrm{SO}_{4}$ and $1 \mathrm{~mL}$ bromide agent were added into the $50 \mathrm{~mL}$ glass tube, which played the role of oxidation and indicator, respectively. After $1 \mathrm{~h}$, a drop of hydroxylamine hydrochloride was added into the tube to deoxidize the residual bromide agent. The MeHg was determined by Tekran Model 2600 with a detection limit of $0.005 \mathrm{ng} / \mathrm{L}$.

Precision and accuracy of the analytical methods were evaluated by comparing the mercury concentrations in certified reference materials to the measured values. The expected and measured concentrations in soil reference (GBW0-70405) were $0.290 \pm 0.003$ and $0.290 \pm 0.0025$ $\mathrm{mg} / \mathrm{kg}$, respectively; in the hair reference (GBW-07601)

Fig. 1 Sample sites

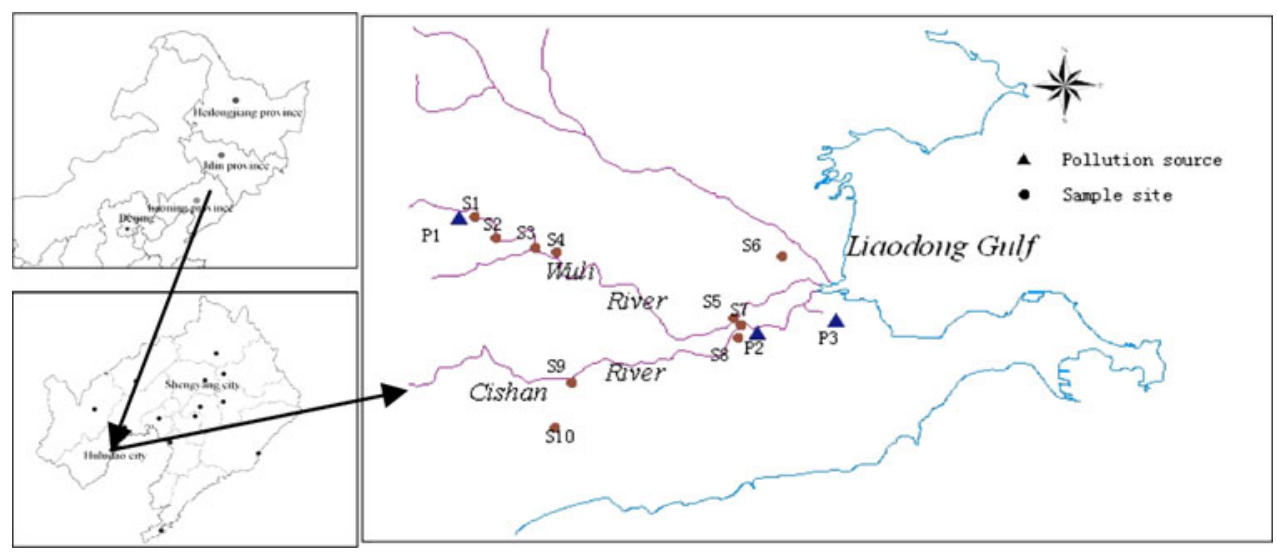


were $0.36 \pm 0.05$ and $0.40 \pm 0.01 \mathrm{mg} / \mathrm{kg}$, respectively. Methyl mercury expected and measured concentrations in reference (IAEA-443) were $0.17 \pm 0.07$ and $0.15 \pm 0.03$ $\mathrm{mg} / \mathrm{kg}$, respectively.

SPSS10.0 for windows and Excel 2003 were used for data analysis and Arcgis9.0 was used to draw the sample map.

\section{Results and Discussion}

Total and methyl mercury concentrations of soil varied from 0.16 to $20.37 \mathrm{mg} / \mathrm{kg}$ (mean, $4.08 \mathrm{mg} / \mathrm{kg}$ ) and from 0.34 to $33.49 \mathrm{ng} / \mathrm{g}$ (mean, $9.17 \mathrm{ng} / \mathrm{g}$ ), respectively (Fig. 2), and varied largely with the sample site (Table 1). No significant correlation was found between total and methyl mercury in soil $(r=0.147, p>0.05)$.

Total mercury concentrations of cicada bodies, wings, and exuviae varied from 0.21 to $9.99 \mathrm{mg} / \mathrm{kg}$ (mean, $2.64 \mathrm{mg} / \mathrm{kg}$ ) in cicada bodies, from 0.20 to $3.72 \mathrm{mg} / \mathrm{kg}$ (mean, $0.98 \mathrm{mg} / \mathrm{kg}$ ) in wings, from 0.08 to $1.95 \mathrm{mg} / \mathrm{kg}$ (mean, $0.50 \mathrm{mg} / \mathrm{kg}$ ) in exuviae, respectively. Methyl mercury concentrations varied from 21.36 to $318.81 \mathrm{ng} / \mathrm{g}$ (mean, $123.93 \mathrm{ng} / \mathrm{g}$ ) in cicada bodies, and varied from 3.61 to $13.15 \mathrm{ng} / \mathrm{g}$ (mean, $7.72 \mathrm{ng} / \mathrm{g}$ ) in exuviae, respectively.

Total mercury concentrations of cicada bodies, wings, and exuviae were found to increase in the order of exuviae $<$ wings $<$ cicada bodies and vary with no significant differences. Methyl mercury concentrations of cicada bodies were about $2.54 \%-25.93 \%$ of total mercury (mean, $4.69 \%)$. For exuviae, the ratios were close to cicada bodies and varied from $0.44 \%$ to $5.72 \%$ (mean, $2.77 \%$ ). The results showed that mercury was almost in inorganic form in cicada bodies.

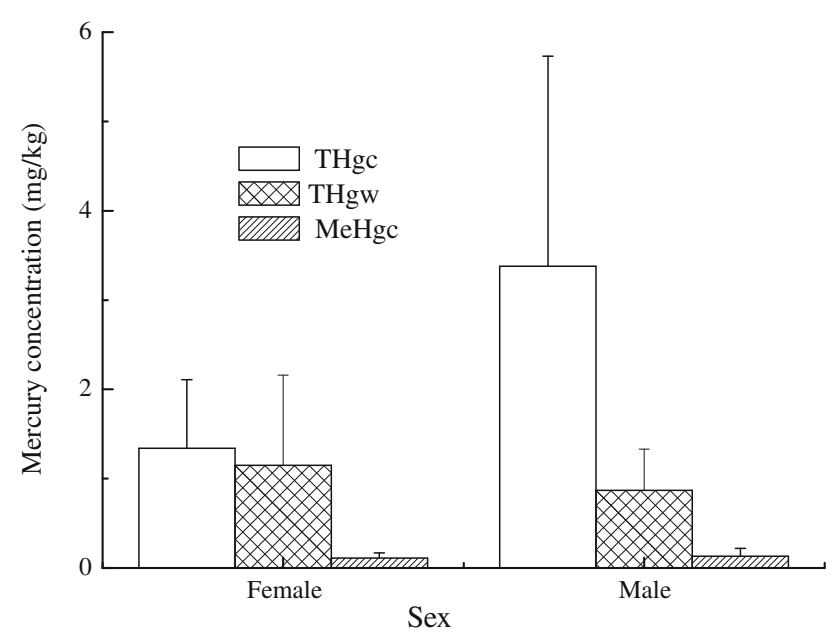

Fig. 2 Sex differences of total and methyl mercury between female and male cicadas
No significant relationship was found between the total and methyl mercury in cicada $(r=-0.442 ; p>0.086)$. It is unknown that whether the cicada directly absorbed methyl mercury from soil or food or methyl mercury was formed in cicada bodies.

Total mercury concentrations of male cicada were significantly higher than those of female $(F=8.433, p<$ $0.01)$, which were much heavier $(F=33.10, p<0.01)$. It was consistent with conclusions past reported (Heckel and Keener 2007) (Table 2).

Correlation analysis showed that neither total nor methyl mercury of cicada was significantly related with the corresponding mercury of soils $(p>0.05)$.

Both the highest total and methyl mercury concentrations of soil were found in Huagong Bridge (S3), where the chlor-alkali plant dumped its effluent in the past. From 1952 to 1980 , the chlor-alkali plant produced $\mathrm{NaOH}, \mathrm{Cl}_{2}$ and $\mathrm{H}_{2}$ using mercury electrodes as one of the main technologies and about $1,500 \times 10^{4} \mathrm{t}$ waste water were discharged into the Wuli River resulting in about $265 \mathrm{t}$ mercury precipitation in the surface sediment and soil (Zhao and Yan 1997). Although the chlor-alkali plant ceased operations using mercury as electrode in 1998, the concentrations of mercury in soil and sediments remains high around site S3. In Daochi village (S6), total and methyl mercury concentrations of soil were slightly lower than those in S3. Daochi village are heavily affected by the mercury atmospheric deposition due to the two zinc smelteries around here. Soil analyzed from site S10, a new residential neighborhood, contained below average total mercury but above average methyl mercury.

In the present work, both the average total and methyl mercury concentrations of cicada bodies were higher than those reported by Heckel and Keener (2007) Compared with the Locusta migratoria manilensis and Acrida chinensis in Huludao City, cicada could accumulate more mercury from the ambient (Table 3). Mercury concentrations of cicada were about 60 and 70 times for total mercury, 10 and 26 times for methyl mercury, of Locusta migratoria manilensis and Acrida chinensis, respectively (Zheng et al. 2008). Cicada are the representative longlived insect species and suffer more mercury exposure than these annual insects. Cicada larvas live underground for about $4-5$ years before the last metamorphosis. Food might be another important reason for high mercury level of cicada. Both Locusta migratoria manilensis and Acrida chinensis feed on plant leaves, but cicada larvas sucks the juice from plant roots of which part the highest mercury concentrations of plant are in Boening (2000).

It is reported that to excrete heavy metals onto the furs, surface skins, and wings might be the mechanisms for animals to endure the heavy metals contaminations (Heliövaara and Väisänen 1990). For example, feathers of birds 
Table 1 Total and methyl mercury of soil, cicada bodies, wings and exuviae

\begin{tabular}{|c|c|c|c|c|c|c|c|}
\hline Site & THgs $(\mathrm{mg} / \mathrm{kg})$ & MeHgs (ng/g) & $\mathrm{THgc}(\mathrm{mg} / \mathrm{kg})$ & THgw $(\mathrm{mg} / \mathrm{kg})$ & THge (mg/kg) & MeHge (ng/g) & $\mathrm{MeHgc}(\mathrm{ng} / \mathrm{g})$ \\
\hline S1 & 0.81 & 3.56 & 3.43 & 0.48 & & & 82.24 \\
\hline $\mathrm{S} 2$ & 2.54 & 6.93 & 0.51 & 1.01 & & & 79.02 \\
\hline $\mathrm{S} 3$ & 8.72 & 22.89 & 2.87 & 1.10 & & & 171.59 \\
\hline $\mathrm{S} 4$ & 2.54 & 5.50 & 1.50 & 1.33 & 1.46 & 6.39 & 157.56 \\
\hline S5 & 5.39 & 7.40 & 0.93 & 0.59 & & & 192.17 \\
\hline S6 & 10.96 & 12.01 & 5.25 & 1.19 & & & 134.88 \\
\hline S7 & 3.36 & 5.71 & 2.51 & 0.48 & & & 172.09 \\
\hline S8 & 0.49 & 5.56 & 8.19 & 0.88 & 0.23 & 13.15 & 27.41 \\
\hline S9 & 0.39 & 0.34 & 1.00 & 1.31 & 0.12 & & 104.43 \\
\hline $\mathrm{S} 10$ & 0.27 & 15.41 & 3.27 & 0.27 & 0.17 & 3.61 & 82.95 \\
\hline
\end{tabular}

THgs, THgc, THgw and THge were the total mercury concentrations in soil, cicada bodies, wings and exuviae; MeHgs, MeHge, and MeHgc were the methyl mercury concentrations in soil, cicada bodies and cicada exuviae

Table 2 Sex difference of cicada body weights, THgc, THgw and MeHgc

\begin{tabular}{llllll}
\hline Sex & $\mathrm{n}$ & Weight $(\mathrm{g})$ & $\mathrm{THgc}(\mathrm{mg} / \mathrm{kg})$ & $\mathrm{THgw}(\mathrm{mg} / \mathrm{kg})$ & $\mathrm{MeHgc}(\mathrm{ng} / \mathrm{g})$ \\
\hline Female & 27 & $0.94-1.31(1.11)$ & $0.21-2.72(1.34)$ & $0.29-3.72(1.15)$ & $31.26-192.17(110.27)$ \\
Male & 40 & $0.35-0.69(0.54)$ & $0.37-9.99(3.38)$ & $0.20-1.50(0.87)$ & $31.38-318.81(132.12)$
\end{tabular}

$\mathrm{THgc}$ and $\mathrm{THgw}$ were the total mercury concentrations in cicada bodies and wings; MeHgc were the methyl mercury concentrations in cicada bodies

Table 3 Total and methyl mercury concentrations comparison with other reports

\begin{tabular}{llll}
\hline Insect & THg $(\mathrm{mg} / \mathrm{kg})$ & $\mathrm{MeHg}(\mathrm{ng} / \mathrm{g})$ & References \\
\hline Locusta migratoria manilensis & $0.013-0.154$ (mean, 0.043) & $1-12$ (mean, 7) & Zheng et al. (2008) \\
Acrida chinensis & $0.009-0.138$ (mean, 0.037) & $1-($ mean, 3) & \\
Paraten-odera sinensis & $0.057-0.117$ & & Hsu et al. (2006) \\
Insect & $0.01-0.26$ (mean, 0.10) & & Heckel and Keener (2007) \\
Magicicada cassini & $0.01-0.05$ & $21.6-318.81$ (123.93) & This paper \\
Cryptotympana atrata & $0.21-9.99$ (mean, 2.64) & & \\
\hline
\end{tabular}

$\mathrm{THg}$ was the total mercury concentration and $\mathrm{MeHg}$ was the methyl mercury concentration

often contain high mercury concentrations Longcore et al. (2007) and the highest mercury concentrations of grasshoppers are in the wings (Zhang et al. 2009). But total mercury concentrations of cicada wings were not high and this might due to their special living habits. Cicada infuses their body fluids to protend wings out after the last metamorphosis and this results total mercury concentrations of wings closed to those of cicada bodies. After their wings generation, cicada could only lived for about 60-70 days above ground which are much shorter than Locusta migratoria manilensis and Acrida chinensis, there might no enough time for cicada to transfer mercury to their wings.

Exuviae is also thought to excrete mercury out from animal bodies. Mercury concentrations of snake exuviae would be $0.4 \mathrm{mg} / \mathrm{kg}$ if snakes received $2.0 \mathrm{mg} / \mathrm{kg}$ mercury exposure per month (Jones and Holladay 2006). Though cicada will experience 5 ecdysis processes during their growth, mercury concentrations and weights of exuviae are low and no appreciable amounts of mercury would be excreted out from cicada bodies. It concludes that exuviae would not effectively reduce mercury poison to cicada.

Results showed mercury concentrations are different with different sex. There might be two possible reasons to explain the sex differences. The female cicada often are heavier than the males and biomass dilutions might reduce mercury concentrations of females. Heckel and Keener (2007) reported that the lower body weights of males resulted in the higher mercury concentrations than females. Another potential reason is that the female lay eggs for generation resulting in possible mercury excretion out from their bodies. No significant sex differences were found on methyl mercury or total mercury concentrations of wings, but methyl mercury concentrations of females were lower 
than those of males while the total mercury concentrations of wings are just contrary (Fig. 2).

The routes of cicada exposed to mercury were not determined in this paper. Heikens has reported that heavy metals in terrestrial invertebrates are related to metal contents in soil (2001). Correlation analysis showed that neither total nor methyl mercury of cicada was related with the corresponding mercury of soils significantly. Heckel and Keener (2007) had assumed the cicada was exposed to mercury through dermal contact, but the hypothesis was not proofed in this paper. We conjecture that cicada ingested mercury from their special food, the fluid of plant root, which part the highest mercury concentrations were found in plants. But it need more detail study to substantiate the guess.

This study showed that mercury pollution in soil and cicada in Huludao City was serious. Cicada could accumulate mercury greatly to high levels. Total and methyl mercury concentrations of soil were not significantly related with each other. In cicada tissues, total mercury were found to increase in the order of exuviae $<$ wing $<$ cicada bodies and methyl mercury in cicada bodies were the highest among them. Methyl mercury concentrations were about $4.69 \%$ of total mercury of cicada bodies and this indicated that most mercury was in inorganic forms in cicada bodies. Sex differences of total mercury concentration were significantly great, total and methyl mercury concentrations of the males were higher. Correlation analysis showed that neither total nor methyl mercury concentrations in cicada bodies were significantly related to the corresponding contents of soil.

Acknowledgments This project is supported by Projects for Remediation of Rivers from Heavy Metal Pollution (No. 2008ZX 07208003-004) and the Innovation Foundation of Chinese Academy of Sciences (No. KZCX3-SW-437).

Open Access This article is distributed under the terms of the Creative Commons Attribution Noncommercial License which permits any noncommercial use, distribution, and reproduction in any medium, provided the original author(s) and source are credited.

\section{References}

Baeyens W, Leermaker M, Papina T, Saprykin A, Brion N, Noyen J, Gieter MD, Elskens M, Goeyens L (2003) Bioconcentration and biomagnification of mercury and methylmercury in North Sea and Scheldt esturay fish. Arch Environ Contam Toxicol 45:498508

Boening DW (2000) Ecological effects, transport, and fate of mercury: a general review. Chemospere 40:1335-1351

Campbell L, Verburg P, Dixon DG, Hecky RE (2008) Mercury biomagnification in the food web of Lake Tangnyika (Tanzania, East Africa). Sci Total Environ 402:184-191

Devkota B, Schmidt GH (2000) Accumulation of heavy metals in food plants and grasshoppers from the Taigetos Mountains, Greece. Agric Ecosys Enviorn 78:85-91

Heckel PF, Keener TC (2007) Sex differences noted in mercury bioaccumulation in Magicicada cassini. Chemoshpere 69:79-81

Heikens A, Peijnenburg WJGM, Hendriks AJ (2001) Bioaccumulation of heavy metals in terrestrial invertebrates. Environ Pollut 113:385-393

Heliövaara K, Väisänen R (1990) Concentrations of heavy metals in the food, faeces, adults, and empty cocoons of Neodiprion sertifer (Hymenopter, Diprionidae). Bull Environ Contam Toxicol 45:13-18

Horai S, Minagawa M, Ozaki H, Watanabe I, Takeda Y, Yamada K, Ando T, Akiba S (2006) Accumulation of $\mathrm{Hg}$ and other heavy metals in the Javan mongoose (Herpestes javanicus) captured on Amamioshima Island, Japan. Chemosphere 65:657-665

Hsu MJ, Selvaraj K, Agoramoorthy G (2006) Taiwan's industrial heavy metal pollution threatens terrestrial biota. Environ Pollut 143:327-334

Jones DE, Holladay SD (2006) Excretion of three heavy metals in the exuviae skin of exposed corn snakes (Elaphe guttata). Ecotoxicol Environ Saf 64:221-225

Longcore JR, Haines TA, Halteman WA (2007) Mercury in tree swallow food, eggs, bodies, and feathers at Acadia National Park, Maine, and an EPA superfund site, Ayer, Massachusetts. Environ Monit Assess 126:129-143

Martin TKT, Wang WX (2004) Uptake and elimination routes of inorganic mercury and methylmercury in Daphnia magna. Environ Sci Technol 38:808-816

Mason RP, Reinfelder JR, Morel FMM (1995) Bioaccumulation of mercury and methyl mercury. Water Air Soil Pollut 80:915-921

Sun J, Chen CY, Li YF, Li B, Gao YX, Chai ZF (2007) Rapid analysis of methylmercury and total mercury in biological samples by ultrasonic-assisted solvent extraction coupled with inductively coupled plasma-mass spectrometry. Spectrosc Spectr Anal 27(1):173-176 (in Chinese)

Zhang ZS, Lu XG, Wang QC, Zheng DM (2009) Mercury, cadmium and lead biogeochemistry in the soil-plant-insect systme in Huludao City. Bull Envion Contam Toxicol 83:255-259

Zhao LD, Yan HF (1997) Mercury pollution of soil along the Wuli River in Huludao City and assessement. Chin J Soil Sci 28(2):68-70 (in Chinese)

Zheng DM, Wang QC, Zhang ZS, Zheng N, Zhang XW (2008) Bioaccumulation of total and methyl mercury by arthoropds. Bull Environ Contam Toxicol 81:95-100 